\title{
Patient's a health care provider satisfactions with out-patients clinics system in fayoum university hospital
}

\begin{abstract}
Background: Satisfaction is one of the main components of quality of care either for patient's or health provider. This study aimed to explore factors affecting the quality of health services provided at Fayoum University Hospital (FUH) outpatient clinics, by assessing patient and health provider's satisfaction with system of work.
\end{abstract}

Methods: The study is a cross-sectional exploratory time bound study; conducted at (FUH) outpatient clinics. A self-administrated questionnaire tapping patientâ $€^{\mathrm{TM}_{\mathrm{S}}}$ satisfaction. Indepth interview with the health care providers about work satisfaction.

Results: $73.5 \%$ and $87.9 \%$ of patients were highly satisfied with the technical quality and financial aspects of service, still, more than two third of patients claimed that the physician did not provide health education. As regards health providers, they were dissatisfied from shortage in numbers of staff members with high case load.

Conclusion: It is concluded that service provider-patient communication/interaction is pivotal and integral part of all hospital care services.

Keywords: healthcare, outpatient, fayoum, adequate food, parameters, ethical considerations, pitaloka
Volume 3 Issue 2 - 2015

\section{Naglaa A El Sherbiny, ' Nargis A Labib, ${ }^{2}$ \\ Douaa A El Derwi, ${ }^{2}$ Eman Hanafy' \\ 'Public Health Department, Fayoum University, Egypt \\ ${ }^{2}$ Public Health Department, Cairo University, Egypt}

Correspondence: Naglaa El-Sherbiny, Fayoum University, Egypt, Tel 01002597806,Email naglaahatem@hotmail.com

Received: October 23, 2015 | Published: December 17, 2015
Abbreviations: FUH, fayoum university hospital; IM, internal medicine; GS, general surgery

\section{Introduction}

Patient's satisfaction is one of the main components of quality of care; it is considered as a major indicator for quality of services. The patient's definition of quality consists of nine elements: good patient care, responsiveness, good doctors, good reputation, up-to-date equipment, cleanliness, adequate food, limited noise, and prompt and accurate billing. ${ }^{1}$ A hospital may be well organized, ideally located and well equipped but it fails to provide quality of care if patient satisfaction is not of a high caliber. ${ }^{2,3}$ Patient's satisfaction with health care service is mainly dependent on the duration and efficiency of care, degree of communication and empathetic with the health care providers. Also, informing patients of the clinical procedures and the time it is expected to take are generally more satisfied even if there is a longer waiting time. ${ }^{4}$

In the past, the medical service providers ran their business by adopting selling orientation rather than customer orientation approach. The supply is more than the demand in medical service market and the patient's perception is arising. Therefore, the medical service administrators adopt customer orientation approach to run their business for creating values of patients and increasing patient satisfaction. ${ }^{5}$ Determining factors associated with patients' satisfaction is thus critical for healthcare providers in order to understand what is valued by patients, how the quality of care is perceived by the patients and to know where, when and how service changes and improvements could be made. ${ }^{6}$ Out-patient department in any hospital is considered to be the window of the hospital. There are various problems faced by the patients in outpatient department like overcrowding, delay in consultation, lack of proper guidance that leads to patient dissatisfaction. $^{7}$

Staff members are responsible for recommending and implementing quality improvement measures. Satisfied employees are excellent representatives of the organization and provide seller service to all customers, and are in turn perceived as high quality by patients. ${ }^{8}$ Accordingly, it is vital that companies understand concepts such as employee engagement and satisfaction and how the levels of engagement and satisfaction relate to customer satisfaction and overall customer experiences, ${ }^{9}$ Quality improvement initiatives were shown to have a positive correlation with employee satisfaction as well as client satisfaction. ${ }^{10}$

\section{Aim of work}

This study aimed to explore factors affecting the quality of health services provided at Internal Medicine and General Surgery outpatient clinics in Fayoum University Hospital by assessing the patient satisfaction with health services and the health care provider's satisfaction with system of work.

\section{Subjects and methods}

The study is a cross-sectional exploratory health service research conducted at Fayoum University Hospital (FUH) outpatient clinics. Fayoum governorate is located in Upper Egypt; $130 \mathrm{Km}$ southwest of Cairo. Situation analysis revealed that the General Surgery (GS) and Internal Medicine (IM) out-patient clinics have the highest flow 
of patients as denoted by the hospital records. Study population consisted of two groups:

1. Patients attending Internal Medicine and General Surgery outpatient clinics, aged above 20 years old, with good general condition, and were able to answer the questions, after receiving the service. .

2. Health care providers working in the clinics (physicians and nurses).

\section{Sample}

1. The patient population frame comprised of all patients attending IM and GS outpatient clinics (according to hospital records estimated to be 27000 patient receiving the service) in the year 2011. Sample size calculation was performed using Open Epi, Version 3, open source calculator which revealed a sample of 379 patient receiving services at the outpatient clinics. This calculation was based on a hypothesized \% frequency of outcome factor in the patient population i.e. satisfaction among patients, to be $50 \%+-5 \%$. A confidence level was set at $95 \%$, the significant level at 0.05 . A sampling interval of 4 was used to systematically select subjects who were recruited to participate in the study. Every fourth patient was invited to participate in the study. A patient's attendance register for each day was made and used as the sampling frame from which patients were selected. The first subject was chosen randomly from this sampling frame, and subsequently every fourth patient was selected and invited to participate. If a selected subject did not meet the inclusion criteria or refused to participate in the study, the next patient was approached until the recommended sample size was recruited.

2. A sample consisting of $50 \%$ of all health care providers at outpatient clinics was included in the in-depth interview.

\section{Study tools included}

A structured questionnaire for patients and in-depth interview with heath care providers.

i. A structured, pretested self-administrated questionnaire consisted of 38 items tapping 6 aspects of satisfaction with care: Administrative and quality of functional performance (15 items), communication and patient rights ( 10 items), and financial aspects (4 items), and time management (4 items) and overall satisfaction (5 items). ${ }^{11}$

ii. The instrument contained both positive and negative words. The questions on patient satisfaction survey were answered using Likert scale (e.g., four points ranging from "strongly agree" to "strongly disagree." Questions included both positively and negatively questions items to minimize the potential bias that occurs from clustering of responses to one side of the scale. The responses were recorded on a four-point scale (range: 1-4) so that higher scores reflect higher patient satisfaction. The responses were grouped and presented as three categories: high satisfaction including the patients, who always agree, moderate satisfaction including the patients who sometimes agree, and then grouping the patients who disagree and uncertain together to represent the dissatisfaction to the quality of service. The scale ratings converted into the following scores: $100,50,0$. the average of these scores were calculated. Each patient had a score for every question answered and a section score is calculated as the mean for all questions.

\section{Health care providers}

In-depth interview with the physician $(\mathrm{N}=35)$ and nurses $(\mathrm{N}=4$ this was the total number of nurses responsible for the clinic) with different years of work experience were asked about: attending training courses, workinghours at the clinic, monitoring of work by senior staff, work environment and infrastructure, the main problems facing them and their suggestions to solve this problem.

\section{Data entry and statistical analysis}

The collected interview questionnaires were revised for completeness and logical consistency. Data were collected, coded and analyzed using SPSS software version 18 under windows 7, and a simple descriptive analysis in the form of percentage distribution, means were done.

\section{Ethical considerations}

This study was reviewed and approved by the Faculty of Medicine Research Ethical Committee. The study was conducted after explaining the aim of the study. All participants had the right not to participate in the study and confidentiality was assured.

\section{Results}

The total number of patients enrolled in the study were $(\mathrm{N}=495)$. 207 patients from GS clinic and 288 from IM clinic. (Response rate was $92.9 \%$ ).

\section{Socio-demographic characteristics}

The studied group $51.7 \%$ female and $48.3 \%$ male patients were involved in the study. Regarding educational level $47.9 \%$ were secondary education and $47.1 \%$ working as a part time also $58 \%$ earned less than 150 pound per month. More than half of the patients attending outpatient clinic of internal medicine $58.2 \%$, and most of them $75.4 \%$ came for follow up visit (Table 1). The current study considers the following parameters for evaluating patient satisfaction: communication, administrative and quality of functional performance, financial and time management.

Communication: Regarding patient- provider communication, $45.1 \%$ of the patients were satisfied as the physician listens to their complain and $41.4 \%$ acknowledged explaining the physician their condition. As regards the patient right of privacy during examination; $68.9 \%$ acknowledged it and $60.8 \%$ revealed that physicians showed respect. More than two third of patients claimed that the physician did not provide health education regarding healthy lifestyle (80.4\%), nor diet regimen related to their medical condition $(79.9 \%)$. The use of medical terms to the patients was recorded by $95.3 \%$.

Administrative and quality of functional performance at outpatient: The above table showed that patients were satisfied by the following points as: $59.2 \%$ were satisfied from the hospital location; accessibility of transportation to the hospital was agreed by $60.4 \%$ of patients, $85.9 \%$ were satisfied by hospital cleanliness, $59.2 \%$ from organization in buying tickets; and $53.7 \%$; $56.6 \%$ of patients were satisfied from entry in an organized manner for imaging investigation and examination respectively. Other patients $79.8 \%$ were unsatisfied from being not choose their physician Table 2 .

Financial aspects: Figure 1 remarked that patients were unsatisfied from high price of; laboratory investigations; medications and radiological investigations as $(82.8 \% ; 54.1 \% ; 51.7 \%)$ respectively. 
Table I Socio-demographic characteristics of studied patients

\begin{tabular}{|c|c|c|}
\hline (\%) & $N=(495)$ & Variable \\
\hline \multicolumn{3}{|c|}{ Gender } \\
\hline 48.3 & 239 & Male \\
\hline 51.7 & 256 & Female \\
\hline \multicolumn{3}{|c|}{ Marital status } \\
\hline 14.3 & 71 & Single \\
\hline 80.2 & 397 & Married \\
\hline 3.4 & 17 & Divorced \\
\hline 2 & 10 & Widow \\
\hline \multicolumn{3}{|c|}{ Occupation } \\
\hline 11.7 & 58 & Full time work \\
\hline 47.1 & 233 & Part time work \\
\hline 31.3 & 155 & Not work \\
\hline 9.1 & 45 & Student \\
\hline 0.8 & 4 & Retired \\
\hline \multicolumn{3}{|c|}{ Clinic } \\
\hline 58.2 & 288 & Internal Medicine \\
\hline 41.8 & 207 & General Surgery \\
\hline \multicolumn{3}{|c|}{ Visit } \\
\hline 24.6 & 122 & Ist \\
\hline 75.4 & 373 & Follow up \\
\hline \multicolumn{3}{|c|}{ Education } \\
\hline 13.5 & 67 & University \\
\hline 47.9 & 237 & Secondary \\
\hline 16.8 & 83 & Can read \& write \\
\hline 21.8 & 108 & Illiterate \\
\hline
\end{tabular}

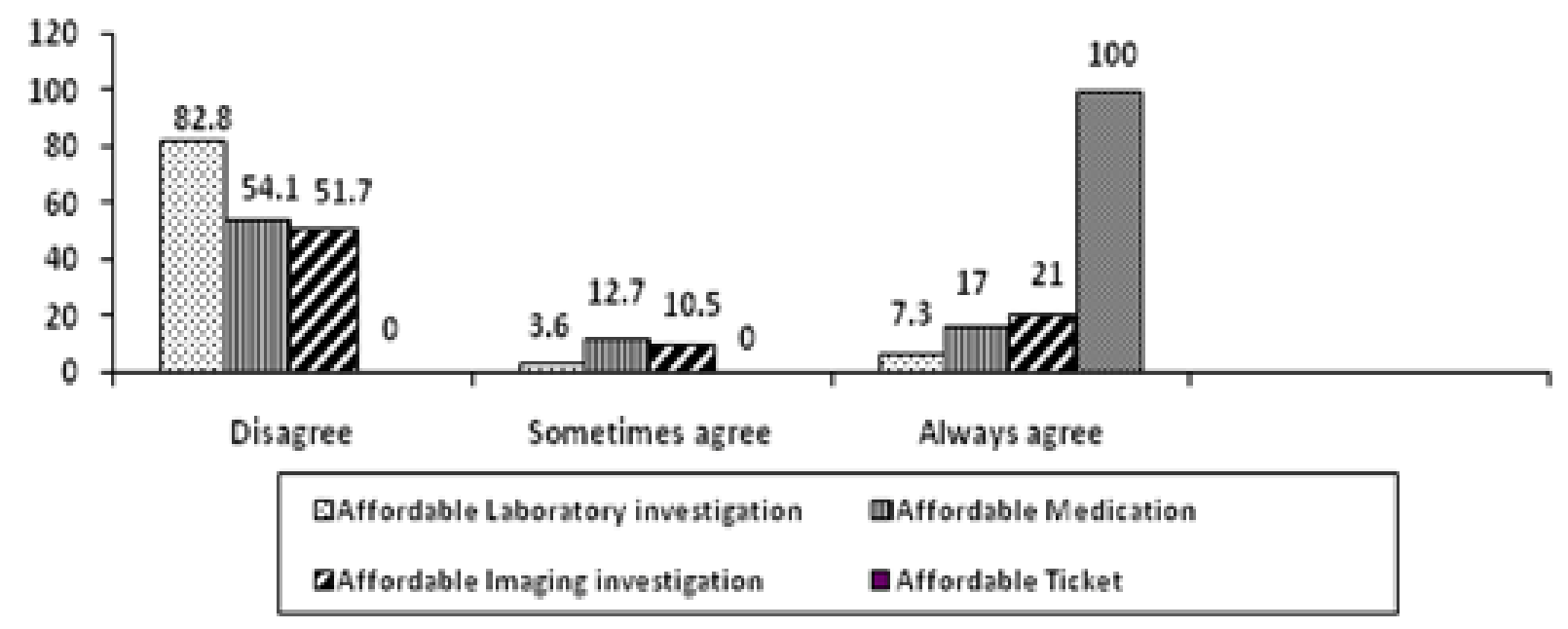

Figure I Patients dissatisfaction regarding financial aspects. 
Table 2 Patients assessment for administrative services

\begin{tabular}{|c|c|c|c|c|c|c|c|c|}
\hline \multirow{2}{*}{ Administrative Services } & \multicolumn{2}{|c|}{ Always Agree } & \multicolumn{2}{|c|}{ Sometimes agree } & \multicolumn{2}{|c|}{ Disagree } & \multicolumn{2}{|l|}{ NA } \\
\hline & $\mathbf{N}$ & $\%$ & $\mathbf{N}$ & $\%$ & $\mathbf{N}$ & $\%$ & $\mathbf{N}$ & $\%$ \\
\hline The hospital is in a good location & 293 & 59.2 & 149 & 30.1 & 33 & 4 & 33 & 6.7 \\
\hline Public Transportation to the hospital is comfortable & 281 & 56.8 & 34 & 6.9 & 168 & 2.4 & 168 & 33.9 \\
\hline The security men guide the patient to service areas at hospital & 109 & 22 & 116 & 23.4 & 246 & 4.8 & 246 & 49.7 \\
\hline The hospital is clean & 425 & 85.9 & 55 & 11.1 & 5 & 2 & 5 & I \\
\hline System for purchase ticket is organized & 293 & 59.2 & 156 & 31.5 & 17 & 5.9 & 17 & 3.4 \\
\hline Receiving Examination service is organized & 280 & 56.6 & 33 & 6.7 & 165 & 3.4 & 165 & 33.3 \\
\hline All imaging investigations are available in the hospital & 167 & 33.7 & 145 & 29.3 & 69 & 23 & 69 & 13.9 \\
\hline All laboratory investigations are available in the hospital & 255 & 51.5 & 27 & 5.5 & 57 & 31.5 & 57 & 11.5 \\
\hline Receiving Imaging investigation organized & 266 & 53.7 & 138 & 27.9 & 16 & 15.2 & 16 & 3.2 \\
\hline Laboratory investigation organized & 255 & 51.5 & 147 & 29.7 & 20 & 14.7 & 20 & 4 \\
\hline The right of choosing physician & 259 & 10.3 & 31 & 6.3 & 395 & 3.6 & 395 & 79.8 \\
\hline Physician assigns appointment to the patient for follow up visit & 259 & 52.3 & 152 & 30.7 & 33 & 10.3 & 33 & 6.7 \\
\hline Physician is always present in follow up visit & 155 & 31.3 & 170 & 34.3 & 84 & 17.4 & 84 & 17 \\
\hline Expectation to find a better care in the hospital & 408 & 82.4 & I & 0.2 & 85 & 0.2 & 85 & 17.2 \\
\hline
\end{tabular}

Time management: Figure 2 showed that $55.8 \%$ expressed dissatisfaction from long waiting time for buying a ticket and for registration $58.6 \%$ of patients said that they took more than 30 minutes for registration. Regarding the overall satisfaction and outcome of care at the hospital $76.4 \%$ said that the waiting area lacked proper facilities; $58.6 \%$ said that there was shortage in some medication and supplies; Only $48.9 \%$ were satisfied with physician performance; $43 \%$ were not satisfied with communication of health care personal. This table revealed that the total satisfaction score showed moderate degree of patient's satisfaction $66.9 \%$. As regards functional quality $73.5 \%$ of patients were highly satisfied. Also $65.3 \%$ and $56.6 \%$ of patients showed moderate degree of satisfaction in communication aspects and in access and continuity of care respectively. However, $87.9 \%$ of patients were unsatisfied from the services price (Table 3 ).

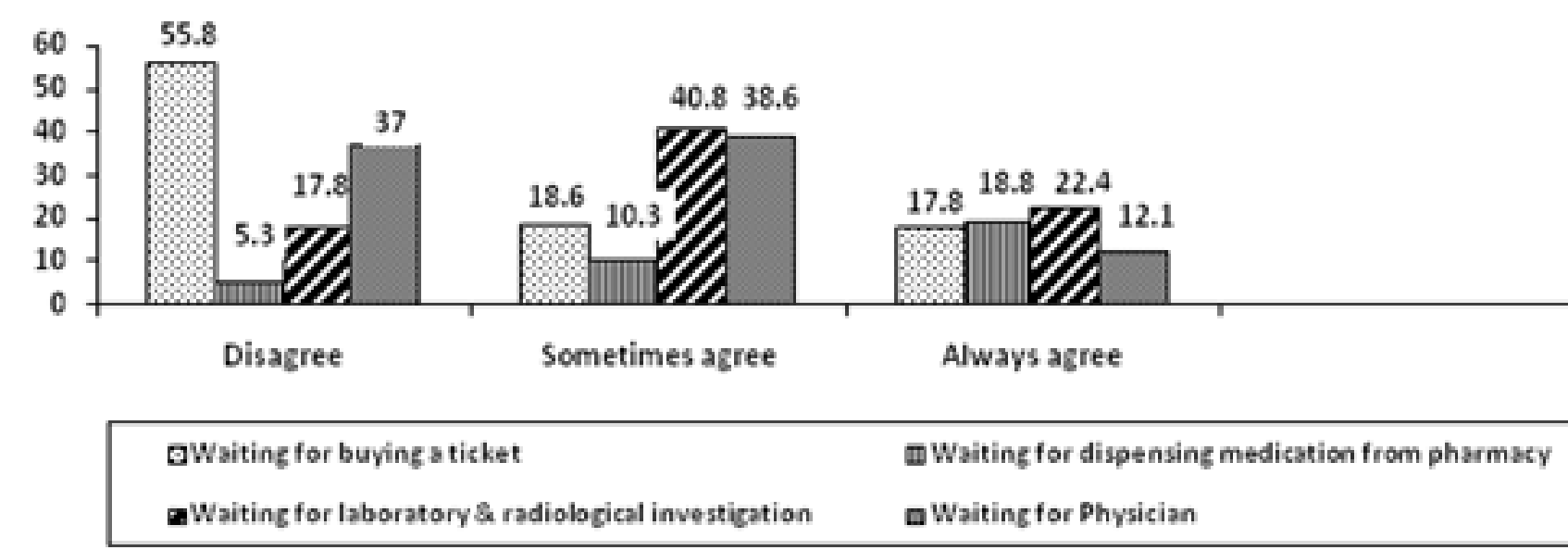

Figure 2 Patients Dissatisfaction from Long Waiting Time.

The health care provider's interview: The response rate was $(60.2 \%)$. The in-depth interview investigated the perception of the physician to the system of work at the outpatient clinics. $94.1 \%$ of physicians reported that nurses were cooperative. All of them stated that the number of attending physicians was not sufficient at the clinic.
About $76 \%$ said that the patients cannot reach the same physician on follow up visits and $85.3 \%$ declared that not all the needed investigations for the patient were available at the hospital as MRI and some laboratory investigations. 
Table 3 Levels of Patients Satisfaction Related to Provided Services

\begin{tabular}{|c|c|c|c|c|c|c|c|}
\hline \multirow{3}{*}{ Satisfaction score (SC) } & \multirow{3}{*}{$\begin{array}{l}\text { SC } \\
\text { Mean } \pm S D\end{array}$} & \multicolumn{6}{|c|}{ Scores } \\
\hline & & \multicolumn{2}{|c|}{ High satisfaction } & \multicolumn{2}{|c|}{ Moderate S. } & \multicolumn{2}{|c|}{ Unsatisfied } \\
\hline & & $\mathbf{N}$ & $\%$ & $\mathbf{N}$ & $\%$ & $\mathbf{N}$ & $\%$ \\
\hline Functional quality performance score & $70.8 \pm 15.6$ & 364 & 73.5 & 76 & 15.4 & 54 & 10.9 \\
\hline Time management score & $64.8 \pm 15.9$ & 42 & 8.5 & 80 & 16.2 & 371 & 74.9 \\
\hline Communication score & $50.5 \pm 14.9$ & 143 & 28.9 & 323 & 65.3 & 29 & 5.9 \\
\hline Access and continuity of care score & $44.4 \pm I 4.5$ & 207 & 41.8 & 280 & 56.6 & 8 & 1.6 \\
\hline Financial aspects score & $39.7 \pm 18.4$ & 3 & 0.6 & 55 & II.I & 435 & 87.9 \\
\hline Total satisfaction score* & $54.5 \pm 6.99$ & 148 & 29.9 & 331 & 66.9 & 10 & 2 \\
\hline
\end{tabular}

The majority of health care providers expressed dissatisfaction from the following: Shortage in numbers of staff members with high case load up to 60 patients/day. Unorganized patient flow (new cases mixed with the follow up cases). Lack of time to communicate well with the patient. Shortage in supplies and equipment's. Absence of patient-centered care. Difficulty for follow up cases to reach their physicians. Lack of a well recording system.

\section{All Health care providers suggested the following}

Setting up of an electronic file system. Decrease the number of examined patients per day. Organize the patient flow using numbers on the tickets. Supply the deficient in supply and equipment's.

\section{Discussion}

The present study aimed to assess the patient-provider satisfaction Measuring user satisfaction in the health service is not a simple task ${ }^{12}$ reported that it is important to evaluate the health care system for many reasons, as improve accountability, raise standard and quality of care, improve responsiveness to patients, monitor health care seeking behaviour, improve patient's compliance with care, and improve outcomes of care. ${ }^{12}$ The study was conducted in outpatient clinics of both GS and IM because the patients flow was high as it represents the first choice for patients before deciding the specialty they will need as the illiteracy rate of Fayoum society was high and most of the patients were not aware about the types of specialties and sub specialties. This is explained by the absence of screening system to guide patients to the appropriate type of care. The current study included measurement of patient satisfaction from communication with health care providers; $45.1 \%$ and $41.4 \%$ and $60.8 \%$ of the patients were satisfied as the physician listen carefully to their complain and explaining clearly their medical condition with respecting them while dealing. However, $80.4 \%$ of patient claimed that the physician didn't inform them about the healthy lifestyle or explain the diet should follow to $79.9 \%$ of the patients and sometimes use medical terms to the patients without explaining with $95.3 \%$ of them. Our results was agreed with a study done by Zewdie ${ }^{13}$ who showed that only $33.3 \%$ of the respondents were given advices on how to prevent the reoccurrence of their current illness and other similar conditions in the future. Only $45.2 \%$ of the patients were told to return if their symptoms get worse.

Lehmann et al., ${ }^{14}$ emphasize the importance of doctor-patient communication that had a positive impact on patient satisfaction. Medical consultations can be influenced by different expectations concerning the doctor-patient interaction associated with the medical situation. As regards administrative results $59.2 \%$ were satisfied from the hospital location; accessibility of transport to the hospital was agreed by $60.4 \%$ of patients, $85.9 \%$ was satisfied by hospital cleanliness, $59.2 \%$ from organization in buying tickets; and $53.7 \%$; $56.6 \%$ of patients were satisfied from entry in an organized manner for imaging investigation and examination respectively. ${ }^{14}$ Our results can be explained by that there was a shortage in the physicians with increased number of patients and the number of physicians at outpatient clinichours was not sufficient to attend the daily clinic load. This will lead to poor patient doctor communication, the patient becomes uncomfortable and low compliance to the treatment this lead to increase unnecessary return visits that subsequently lead to increase case load.

Bentur et al. ${ }^{15}$ revealed that the cost of care has also been found to be a reason for dissatisfaction with access to care.$^{15}$ And they found that the higher the cost, the lower the level of patient satisfaction. our results were in agreement with the previous statement regarding price of medications; radiological and laboratory investigations; with a contradiction with ${ }^{16}$ who documented that at Pakistan Railways Hospital $96.1 \%$ were satisfied with the laboratory services at hospital and $95.3 \%$ rated ultrasound and radiological services as satisfactory. The studied patients $55.8 \%$ expressed dissatisfaction from long waiting time for buying a ticket and $93.3 \%$ claimed that the physician didn't stay with them enough time. This result was agreed by the ${ }^{17}$ result reported that $57 \%$ of his study patients were waiting for long hours (3hours) with a delayed waiting time for consultation. As the waiting time is variable ${ }^{18}$ considered in his study that patients waiting more than 75 minutes were considered too unreliable.

Kumar \& Zahra ${ }^{19}$ explained that patients often dissatisfied when their needs and expectations which are based on their experiences, environment, social background and personality are not fulfilled. ${ }^{19}$ This was in agreement with the overall satisfaction and outcome of care at the hospital as $76.4 \%$ said that the number of chairs at the waiting area was few; $58.6 \%$ said that there was shortage in some medication and supplies; $43 \%$ were not satisfied with communication of health care personal but $48.9 \%$ were satisfied with physician performance which is almost equal to the results of ${ }^{20}$ in Qassim showed that the satisfaction score was $45.66 \%$ regarding the technical competency of the providers and below the results of ${ }^{13}$ that $35 \%$ the respondents strongly disagreed about the technical competency of the providers. (Table 2) revealed that the total satisfaction score 
showed moderate degree of patient's satisfaction $66.9 \%$ with a $87.9 \%$ and $73.5 \%$ of patients were highly satisfied by technical quality and financial aspect. These satisfaction scores are more than similar studies conducted in Kuwait for the physician services, which scored $44.2 \%$ were un satisfied ${ }^{21}$ and other studies which were conducted in Riyadh and Jeddah cities Saudi Arabia, but are much lower than the reported findings from global studies, which ranged from $61 \%$ to $97 \%$ were un satisfied. In the current study, the majority of Health care providers expressed dissatisfaction from shortage in numbers of staff members with long working hours. And they have suggested increasing the number of physicians at the clinic. This was agreed by Rosta $^{22}$ results based on a national sample of hospital physicians in Germany found that the majority of health care providers were unsatisfied from long working hours lclinic up to 6hours then continue the rest of the day at the inpatient. Also ${ }^{23}$ focused on the importance of appointment scheduling in healthcare to deal with high caseload. Also $76.5 \%$ of the physicians said that the cases cannot easily reach their physician easily. Our results explained by Ouwens ${ }^{24}$ said that having appointments with the same doctor promotes better continuity of care, which is an essential factor in order for people with chronic conditions to be satisfied with access.

\section{Conclusion}

The current study showed that patient and health care provider's satisfaction is crucial for continues quality improvement of health system. Teamwork building and establish of electronic medical record system is important to establish continuity of care. Service providerpatient communication/interaction is pivotal and integral part of all hospital care services that significantly influence patient satisfaction.

\section{Acknowledgements}

None.

\section{Conflict of interest}

The author declares no conflict of interest.

\section{References}

1. Chilgren AA. American College of Health care Executives Audience: Business; Health care industry. Journal of Health care Management. 2008:53(4).

2. Tarantino D. How should we measure patient satisfaction? Physician Executive. 2004;30(4):60-61.

3. Alzolibani AA. Patient satisfaction and expectations of the quality of service of University affiliated dermatology clinics. Journal of Public Health and Epidemiology. 2011;3(2):61-67.

4. Pulia M. Simple tips to improve patient satisfaction. Common sense (Newsletter of the AAEM). 2011;18(1):18-19.

5. Lee W, Cheng Wu C, Kung-Hsing C, et al. The relationship between consumer orientation, service value, and medical care service quality and patient satisfaction: The case of a medical center in Southern Taiwan. African Journal of Business Management. 2010;4(4):448-458.

6. De Jager JW, Du Plooy AT, Ayedi FM. Delivering quality service to in and out-patients in a South Africa public hospital. African Journal of Business Management. 2010;4(2):133-139.
7. Srinivasan AV. Managing a Modern Hospital. India: Response Books A Division of Saga Publishers, India (P) Ltd; 2000. p. 53-69.

8. Solberg LI, Crain AL, Sperl-Hillen JM, et al. Improved primary care access: how does it affect depression care quality? Ann Fam Med. 2006;4(1):69-74.

9. Newman K, Maylor U, Chansarkar B. The nurse retention, quality of care and patient satisfaction chain. International Journal of Health Care Quality Assurance. 2001;14(2):57-64.

10. Kammerlind P, Dahlgaard J, Rutberg H. Climate for improvement and the effects on performance in Swedish healthcare-a survey in the County Council of Ostergotland. Total Quality Management \& Business Excellence. 2004;15(7):909-924.

11. Gadallah M, Zaki B, Rady M, et al. Patient satisfaction with primary health care services in two districts in lower and Upper Egypt. Eastern Mediterr Health J. 2003;9(3):422-430.

12. Pitaloka DS, Rizal AM. Patients satisfaction in Antenatal Clinic Hospital University Kebangsaan Malaysia. Journal Kesihatan Masyarakat. 2006;12(1):9-18.

13. Zewdie B, Tsion A, Eshetu G, et al. Determinants of satisfaction with health care provider interactions at health centres in central Ethiopia: a cross sectional study. BMC Health Services Research. 2010;10:78.

14. Lehmann $\mathrm{C}$, Koch U, Mehnert A. Impact of the doctor-patientcommunication on distress and utilization of psychosocial services among cancer patients. A review of the current literature. Psychother Psychosom Med Psychol. 2009;59(7):e3-e27.

15. Bentur N, Gross R, Brammli GS. Satisfaction with and access to community care of the chronically ill in Israel's health system. Health Policy. 2004;67(2):129-136.

16. Awwab OK, Iqbal M, Abdul Ghani W. Patients Experience and Satisfaction with Healthcare at Pakistan Railways Hospital, Rawalpindi Ann. Pak Inst Med Sci. 2012;8(2):122-124.

17. Jawahar SK. A study on out patient satisfaction at a super speciality hospital in India. Internet Journal of Medical Update. 2007;2(2):13-17.

18. Camacho F, Anderson R, Safrit A, et al. The Relationship between Patient's Perceived Waiting Time and Office-Based Practice Satisfaction. NC Med J. 2006;67(6).

19. Kumar MP, Zahra M. Factors affecting patient satisfaction among those attending an out patient department in Chennai city - India. JIAPHD. 2008;12:15-19.

20. Aldebasi YH, Issa MA. Patients' Satisfaction with Medical Services in the Qassim Area. Journal of Clinical and Diagnostic Research. 2011;5(4):813-817.

21. Saeed AA, Mohammed BA, Magzoub ME, et al. Satisfaction and the correlates of the patients' satisfaction with physician services in primary health centers. Saudi M J. 2001;22(3):262-267.

22. Rosta J, Gerber A. Excessive working hours and healths complaints among hospital physicians. Ger Med Sci. 2007:(5).

23. Murray M, Davies M, Boushon B. Panel size: How many patients can one doctor manage? Fam Pract Manag. 2007;14(4):44-51.

24. Ouwens $\mathrm{M}$, Wollersheim $\mathrm{H}$, Hermens $\mathrm{R}$, et al. Integrated care programmes for chronically ill patients: a review of systematic reviews. International Journal of Quality Health Care. 200517(2):141-146. 